\title{
Inhibitor of Nuclear Factor Kappa-B Kinase Subunit Beta
}

National Cancer Institute

\section{Source}

National Cancer Institute. Inhibitor of Nuclear Factor Kappa-B Kinase Subunit Beta. NCI

Thesaurus. Code C96385.

Inhibitor of nuclear factor kappa-B kinase subunit beta (756 aa, $\sim 87 \mathrm{kDa}$ ) is encoded by the human IKBKB gene. This protein is involved in serine phosphorylation, signal transduction and apoptosis inhibition. 